\title{
Larval development of Chthamalus malayensis (Cirripedia: Thoracica) reared in the laboratory
}

\author{
Yan Yan* and Benny K.K. Chan \\ Department of Ecology \& Biodiversity and The Swire Institute of Marine Science, \\ The University of Hong Kong, Pokfulam Road, Hong Kong. \\ *E-mail: yany@hkusua.hku.hk
}

\begin{abstract}
Larvae of Chthamalus malayensis (Cirripedia: Thoracica) from Hong Kong were cultured in the laboratory. Larval development includes six naupliar stages and a non-feeding cypris stage. Larvae reached the cypris stage in $20 \mathrm{~d}$ at $\sim 21^{\circ} \mathrm{C}$ compared to $14 \mathrm{~d}$ at $\sim 28^{\circ} \mathrm{C}$. Morphological features including the cephalic shield, frontal horns, labrum, abdominal process, antennules, antennae and mandibles in all nauplius and cypris stages were described and illustrated using a combination of light microscopy and scanning electron microscopy. Attempts were made to compare morphological differences between the nauplii and cyprid of $C$. malayensis with those of other Chthamalus species including C. stellatus, C. montagui, C. dentatus, C. fragilis, C. dalli, C. antennatus, C. fissus and C. challengeri. The present description of the nauplii of $C$. malayensis is not in agreement with the previous description of this species.
\end{abstract}

\section{INTRODUCTION}

Chthamalus malayensis Pilsbry (1916) is an intertidal barnacle common in the Indo-Pacific region (Pope, 1965). In Hong Kong, C. malayensis inhabits the high intertidal on exposed, oceanic shores (Morton \& Morton, 1983). The larvae of only nine Chthamalus species have been described, namely C. stellatus (Bassindale, 1936; Daniel, 1958; Burrows et al., 1999); C. montagui (Burrows et al., 1999); C. dentatus (Achituv, 1986); C. malayensis (Karande \& Thomas, 1976); C. fragilis (Lang, 1979); C. dalli (Korn \& Ovsyannikova, 1979; Miller et al., 1989); C. antennatus (Egan \& Anderson, 1989); C. fissus (Miller et al., 1989) and C. challengeri (Lee, 1999). Although the larval development of $C$. malayensis has been reported from the Indian Ocean (Karande \& Thomas, 1976), this description is not detailed, as light microscope examination alone of the larval development of barnacles has been found to be inadequate. To maximize taxonomic resolution, descriptions of barnacle larvae often involve the use of scanning electron microscopy (SEM) to investigate larval structures in more detail (e.g. frontal horns, surface sculpture, and antennular segment and carapace of the cyprid) and to discover more diagnostic characters of species (see Rainbow \& Walker, 1976; Walker \& Lee, 1976; Clare \& Nott, 1994; Elfimov, 1995; Glenner \& Høeg, 1995; Moyse et al., 1995; Walossek et al., 1996; Karande, 1999).

This paper presents observations made with both light microscopy and SEM of morphological characteristics of the nauplii and cypris larvae of Chthamalus malayensis reared in the laboratory. Morphological differences between the nauplii and cyprids of this species from Hong Kong and Mumbai, India (Karande \& Thomas, 1976) are compared. A detailed comparison of the described larvae of other members of the genus Chthamalus is also included.

\section{MATERIALS AND METHODS}

\section{Larval rearing}

Adult Chthamalus malayensis were collected in MayNovember 2000 from high intertidal rocks at Cape d'Aguilar, on the south-east coast of Hong Kong island. Egg masses containing embryos with eyes were removed from mantle cavities and transferred to filtered seawater containing $50 \mu \mathrm{g} \mathrm{ml}^{-1}$ streptomycin sulphate (to inhibit Gram-negative bacteria) and $10 \mu \mathrm{g} \mathrm{ml}^{-1}$ penicillin (to inhibit Gram-positive bacteria) (Landau \& d'Agostino, 1977).

Hatched larvae were cultured in 1-1 autoclaved glass vessels maintained in culture cabinets under $14 \mathrm{~h}$ light: $10 \mathrm{~h}$ dark photoperiod and temperatures of $21 \pm 2$ or $28 \pm 2{ }^{\circ} \mathrm{C}$. These two temperatures covered the range of Hong Kong seawater temperatures during the reproductive season (Morton \& Morton, 1983). Autoclaved seawater (30 psu) containing antibiotics was changed every three days, and larvae were fed with the flagellate Isochrysis galbana at $1 \times 10^{5}-5 \times 10^{5}$ cells $\mathrm{ml}^{-1}$ concentration.

During the larval development, 30 larvae at each stage (stage I to cyprids) were collected and preserved in 30\% ethanol in order to monitor their morphological characters (Miller, 1994). Preserved exuviae and larvae were dissected with fine needles and observed under a light microscope. Drawings were made using a camera lucida attachment and measurements made with a calibrated ocular micrometer. The total length of the nauplii was measured from the frontal margin of the cephalic shield 
to the tip of the dorsal thoracic spine or abdominal process, whichever was longer. The shield width of the nauplii was measured at its widest point and shield length from the anterior margin of the shield to the posterior border. The width (depth) of the cypris larvae was measured as the maximum distance between the dorsal and ventral margins of the carapace at the deepest point, and cypris length from the anterior to the posterior carapace margins. The morphology of the antennules, antennae and mandibles was described using the setation formulae of Newman (1965) and setal terminology based on Lang (1979) and Branscomb \& Vedder (1982).

\section{Scanning electron microscopy (SEM)}

The structure and surface sculpturing of the carapace, labrum, frontal horns and thoraco-abdominal processes were investigated using the scanning electron microscope (SEM, Leica Stereoscan 440). Larvae were fixed in 2.5\% glutaraldehyde (in seawater) for $1 \mathrm{~h}$, rinsed in distilled water for $1 \mathrm{~min}$, then dried progressively in graded ethanols $(30,50,75,95$ and 100\%), critical-point dried and coated in gold-palladium before observation using SEM.

\section{RESULTS \\ Larval culture and development}

Larval development of Chthamalus malayensis consists of six naupliar stages and a non-feeding cypris stage. Larval development from stage I to cyprid took $20 \mathrm{~d}$ at $21 \pm 2^{\circ} \mathrm{C}$ and $14 \mathrm{~d}$ at $28 \pm 2^{\circ} \mathrm{C}$ (Table 1 ).

\section{Larval morphology of Chthamalus malayensis}

Nauplii of C. malayensis have a convex, globular cephalic shield with a posterior spine at stages II and III; the posterior spine is absent from stages IV to VI. The frontolateral horns are directed ventrally and the unilobed labrum bears numerous teeth. The caudal processes are considerably shorter than the cephalic shield itself. In addition to common simple (S) and plumose $(\mathrm{P})$ setae, the mandibles bear cuspidate $(\mathrm{C})$ setae and the antennae possess one hispid $(\mathrm{H})$ and several feathered (F) setae. Setal formulae (after Newman, 1965) are given in Table 2.

Naupliar length increased from $239 \mu \mathrm{m}$ at stage I to $526 \mu \mathrm{m}$ at stage VI (Table 3), while cyprid length ranged

Table 1. Time taken (days) for the appearance of the larval stages of Chthamalus malayensis at the two culture temperatures.

\begin{tabular}{|c|c|c|c|c|c|c|c|}
\hline \multirow[b]{2}{*}{ Culture temperature $\left({ }^{\circ} \mathrm{C}\right)$} & \multicolumn{7}{|c|}{ Larval stage } \\
\hline & I & II & III & IV & $\mathrm{V}$ & VI & Cyprid \\
\hline $21 \pm 2$ & 1 & 1 & 4 & 6 & 9 & 14 & 20 \\
\hline $28 \pm 2$ & 1 & 1 & 2 & 4 & 7 & 10 & 14 \\
\hline
\end{tabular}

I-VI, naupliar stages.

Table 2. Setal formulae for the nauplii of Chthamalus malayensis.

\begin{tabular}{llllll}
\hline $\begin{array}{l}\text { Naupliar } \\
\text { stage }\end{array}$ & Antennule & $\begin{array}{l}\text { Antenna } \\
\text { exopod }\end{array}$ & Endopod & $\begin{array}{l}\text { Mandible } \\
\text { exopod }\end{array}$ & Endopod \\
\hline I & S.SSS:SS.S:S & S:4S & 3S:2S:2S:2S:G & S:3S & 3S:2S:2S.2S:G \\
II & 2SPS:SP.P:S & SP:4P:S & 2PS.2S:2F:SFH:G & P:3P:S & 3S.SP:PGP:2P:G \\
III & S.PSPS:SP.P:S & 2P:5P & P3S:2S:2F:SFPH:G & P:3P:S & 3S.SPS:PGP:PCP:G \\
IV & S.P.PSPS.SP:P:S & 2P:7P & P4S:3S:FSF:SFPH:G & P:4P & 4S:SPP:PCP:PGP:G \\
V & S:P.P.PSPS.SP:S.P:S & 3P:8P & 2PS2P:4S:FPF:SFPH:G & P:4P:S & 5S:SPSP:PCP:PCP:G \\
VI & S:P.P.PSPS.SP:P.PS:S & 4P:8P & 2PS2P:5S:SFFFS:SFPH:G & P:5P & 5S:SPSP:SPCP:PCP:G
\end{tabular}

Setal types: S, simple; P, plumose; C, cuspidate; G, gnathobase; H, hispid; F, feathered.

Table 3. Dimensions of cultured larval stages of Chthamalus malayensis.

\begin{tabular}{|c|c|c|c|c|c|c|c|}
\hline \multirow[b]{2}{*}{ Stage } & \multirow[b]{2}{*}{$\mathrm{N}$} & \multicolumn{2}{|c|}{ Total length $(\mu \mathrm{m})$} & \multicolumn{2}{|c|}{ Shield width $(\mu \mathrm{m})$} & \multicolumn{2}{|c|}{ Shield length $(\mu \mathrm{m})$} \\
\hline & & Mean \pm SD & Range & Mean \pm SD & Range & Mean \pm SD & Range \\
\hline I & 30 & $239 \pm 12$ & $225-260$ & $126 \pm 7$ & $120-140$ & & \\
\hline II & 30 & $332 \pm 10$ & $320-340$ & $217 \pm 9$ & $210-225$ & & \\
\hline III & 30 & $379 \pm 15$ & $350-390$ & $267 \pm 10$ & $255-280$ & & \\
\hline IV & 30 & $428 \pm 10$ & $410-445$ & $310 \pm 10$ & $290-320$ & $312 \pm 9$ & $310-330$ \\
\hline $\mathrm{V}$ & 30 & $475 \pm 17$ & $440-490$ & $350 \pm 11$ & $330-370$ & $342 \pm 24$ & $310-385$ \\
\hline VI & 30 & $526 \pm 19$ & $490-510$ & $424 \pm 16$ & $400-450$ & $429 \pm 13$ & $420-450$ \\
\hline Cyprid & 20 & $425 \pm 13$ & $410-440$ & $221 \pm 9$ & $210-230$ & & \\
\hline
\end{tabular}



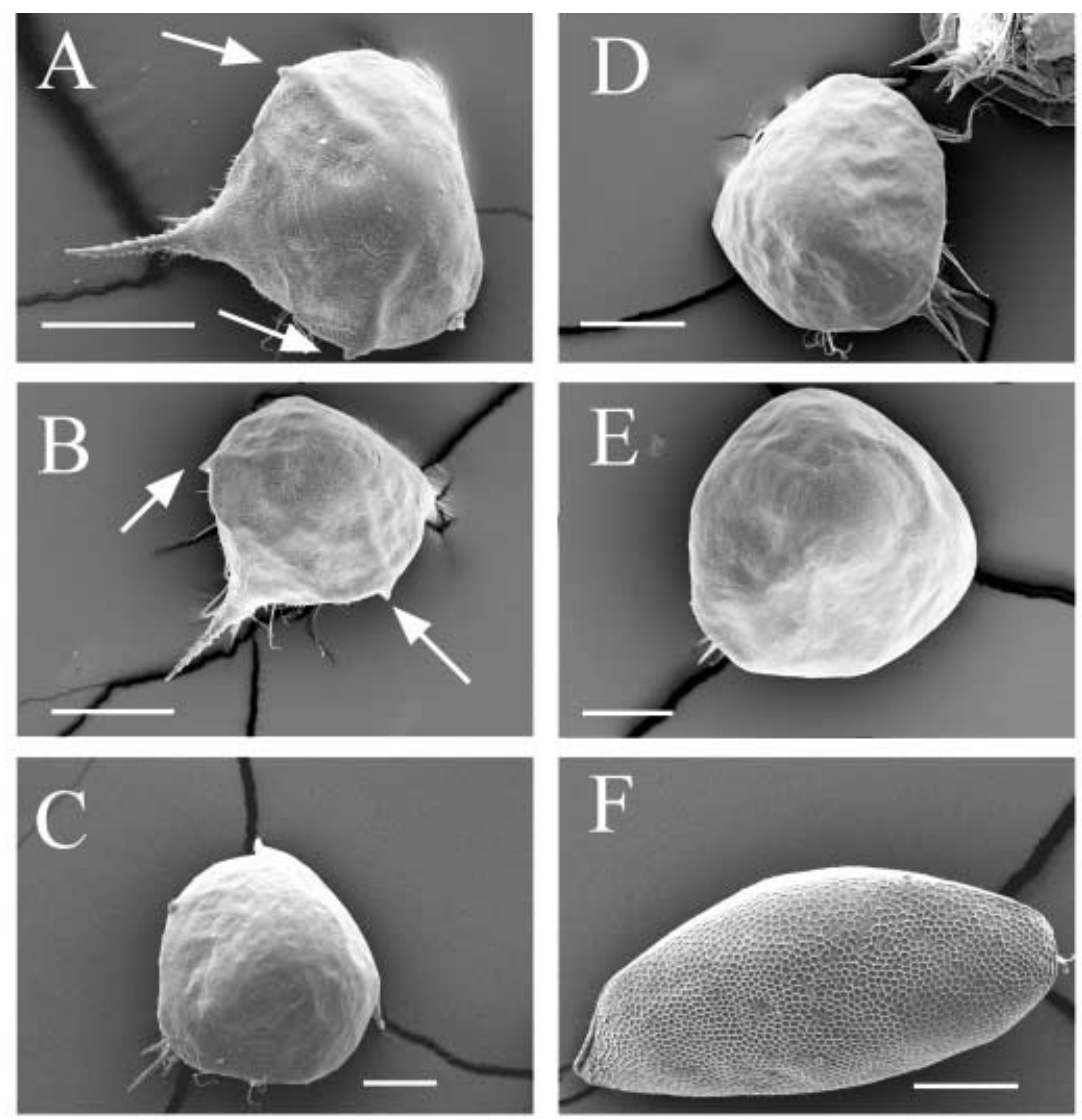

Figure 1. Body forms (dorsal shield outline) of larvae of Chthamalus malayensis: (A-F) representing naupliar stages II-VI and cyprid. Note the presence of lateral gland spine (indicated by arrows). Scale bar: $100 \mu \mathrm{m}$.
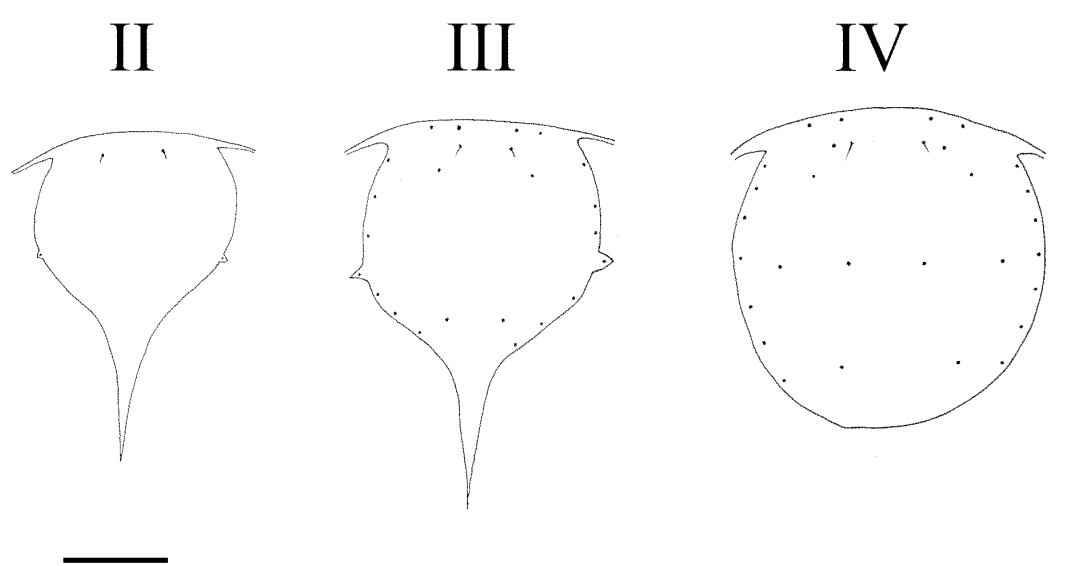

Figure 2. The position of the pores and setae on the dorsal cephalic shield of naupliar stage II, III and IV recorded under SEM investigation. Scale bar: $100 \mu \mathrm{m}$.

from $410-440 \mu \mathrm{m}$ (Table 3). The detailed morphological characteristics of the larvae are as follows:

\section{Nauplius $I$}

This larval stage has a mean length of $239 \pm 12 \mu \mathrm{m}$. The pear-shaped cephalic shield has a pair of anterior frontolateral horns folded back parallel with the long axis of the body and a dorsal thoracic spine. No frontal filaments were observed. The labrum is smooth and has no teeth. The dorsal thoracic spine and abdominal processes are blunt and similar in length. The setae are simple, but many small spines decorate all appendages when observed under SEM.

\section{Nauplius II}

The cephalic shield (Figure 1A) has become extended in length $(332 \mu \mathrm{m})$ and convex in shape. A pair of lateral gland spines was observed (Figure 1A). The anterior shield margin is smooth, but the posterolateral shield margin is spinulated with 5-9 fine spines. No pores were observed on the dorsal surface of the cephalic shield, but a pair of setae was recorded on the frontal 

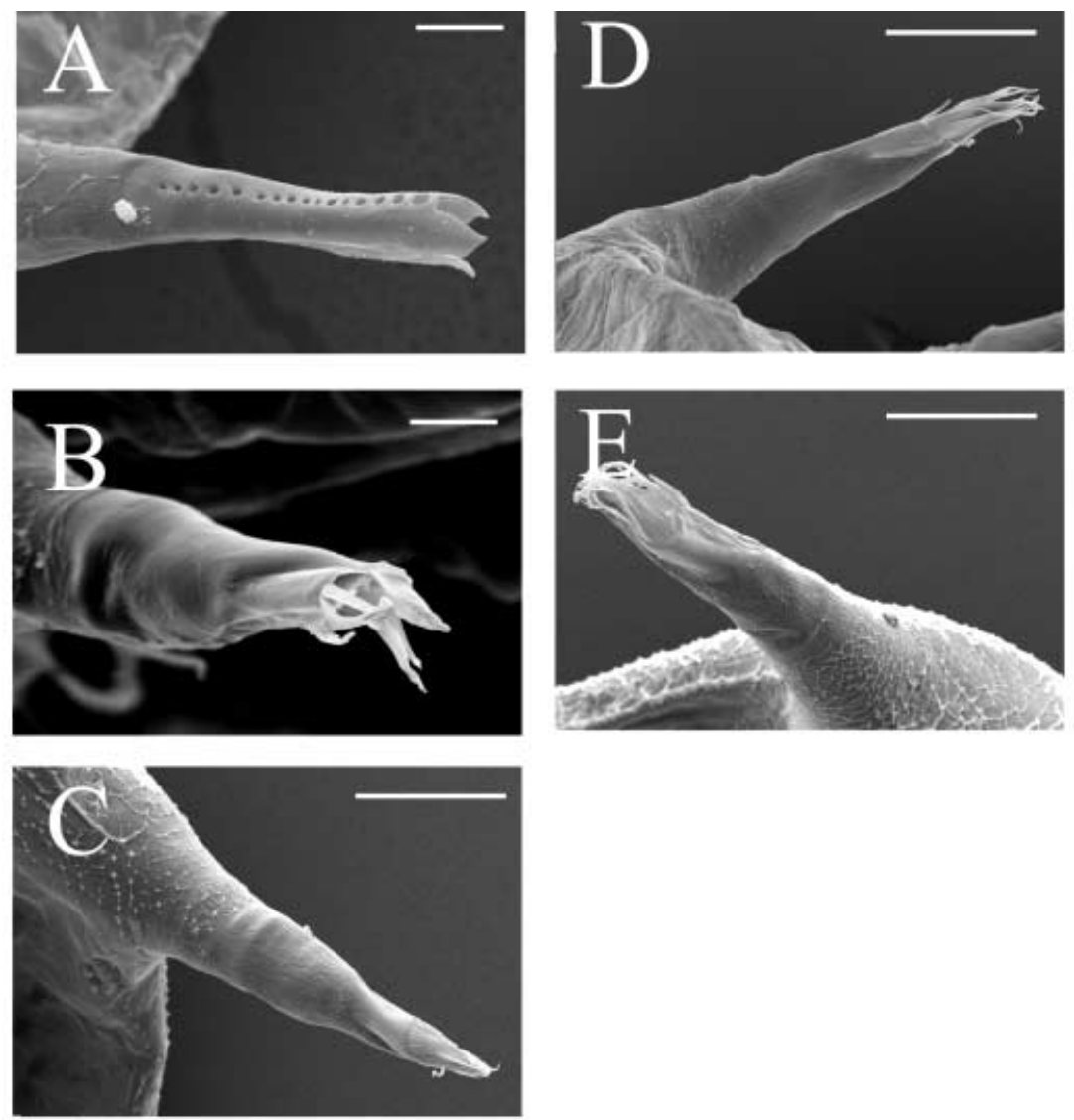

Figure 3. Frontal horns of larvae of Chthamalus malayensis under SEM: (A-E) of naupliar stages II-VI. Note the pores are only present at stage II. Scale bar: $10 \mu \mathrm{m}$.
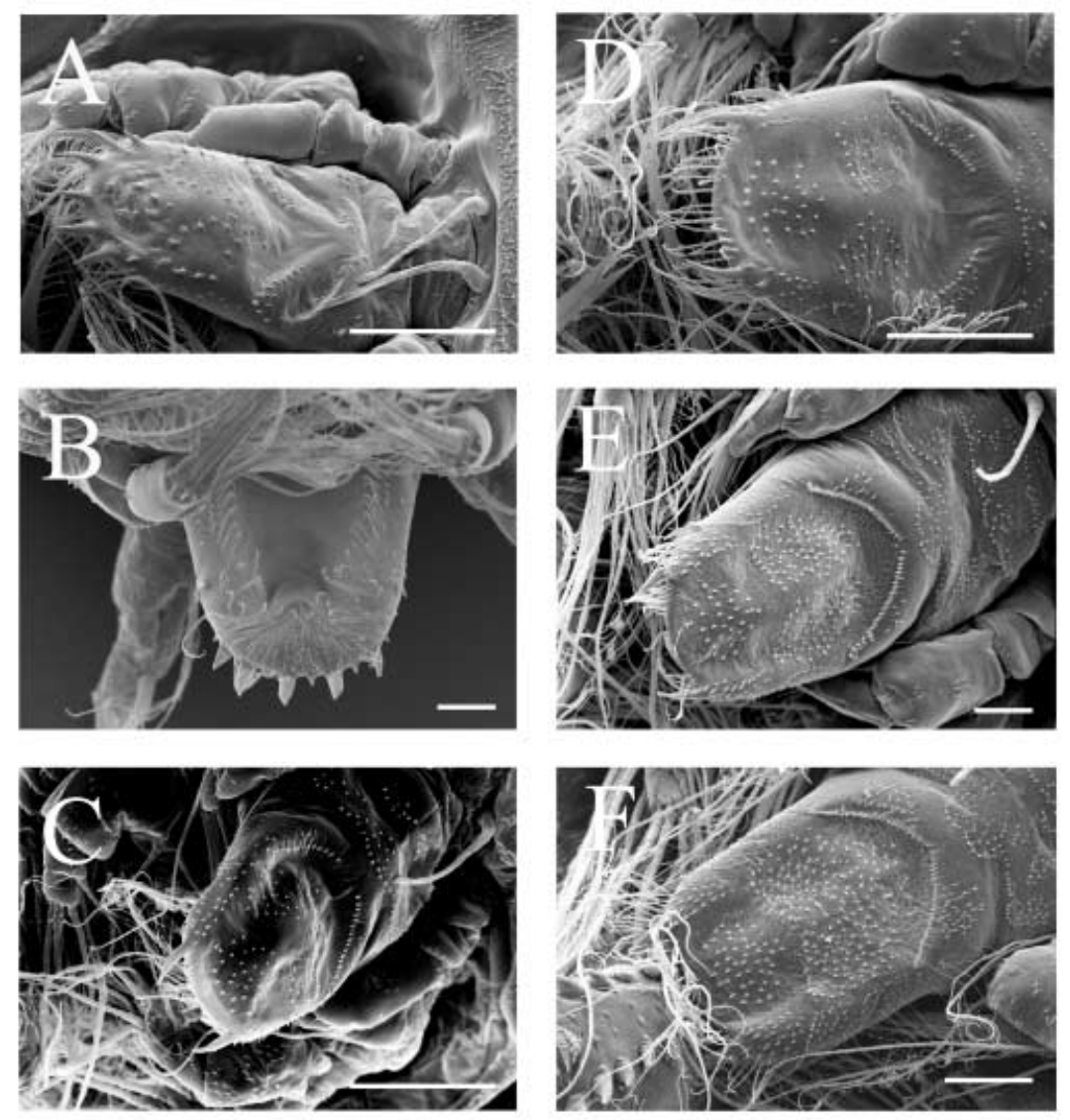

Figure 4. Labrum of naupliar stages II to VI of Chthamalus malayensis: (A,C-F) ventral views; and (B) dorsal view of naupliar stages II. Scale bar: $10 \mu \mathrm{m}$. 
Larval development of Chthamalus malayensis $\quad$ Y.Yan and B.K.K. Chan 627

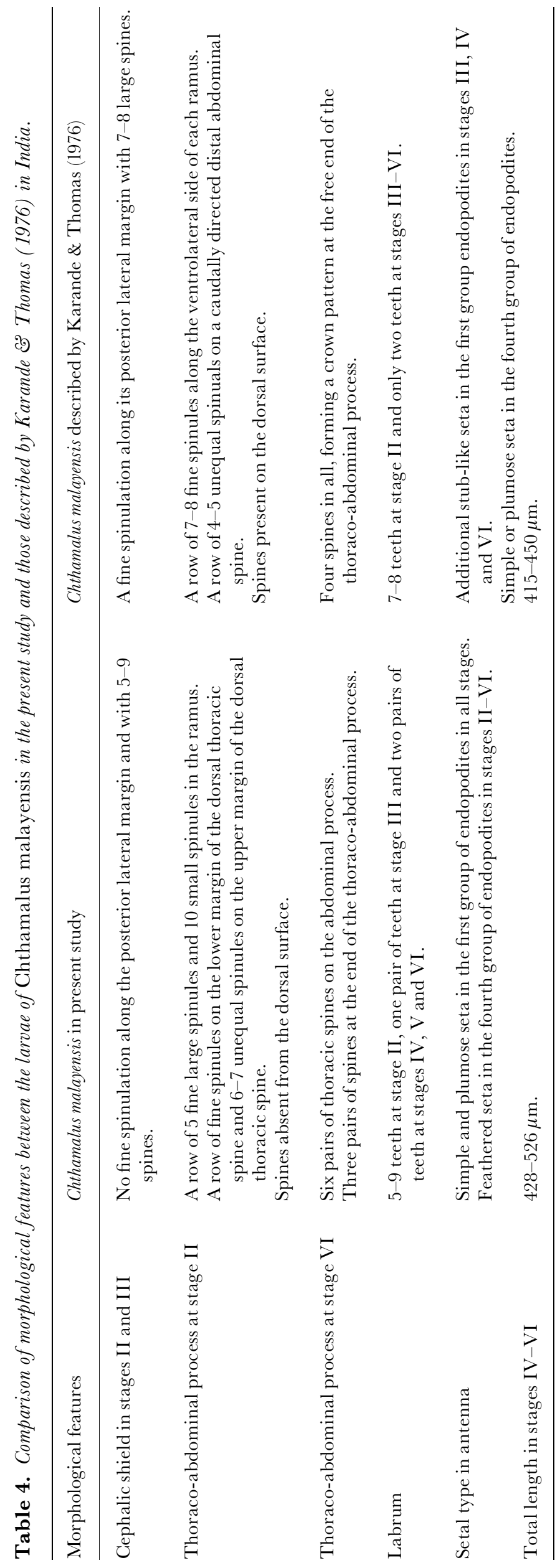



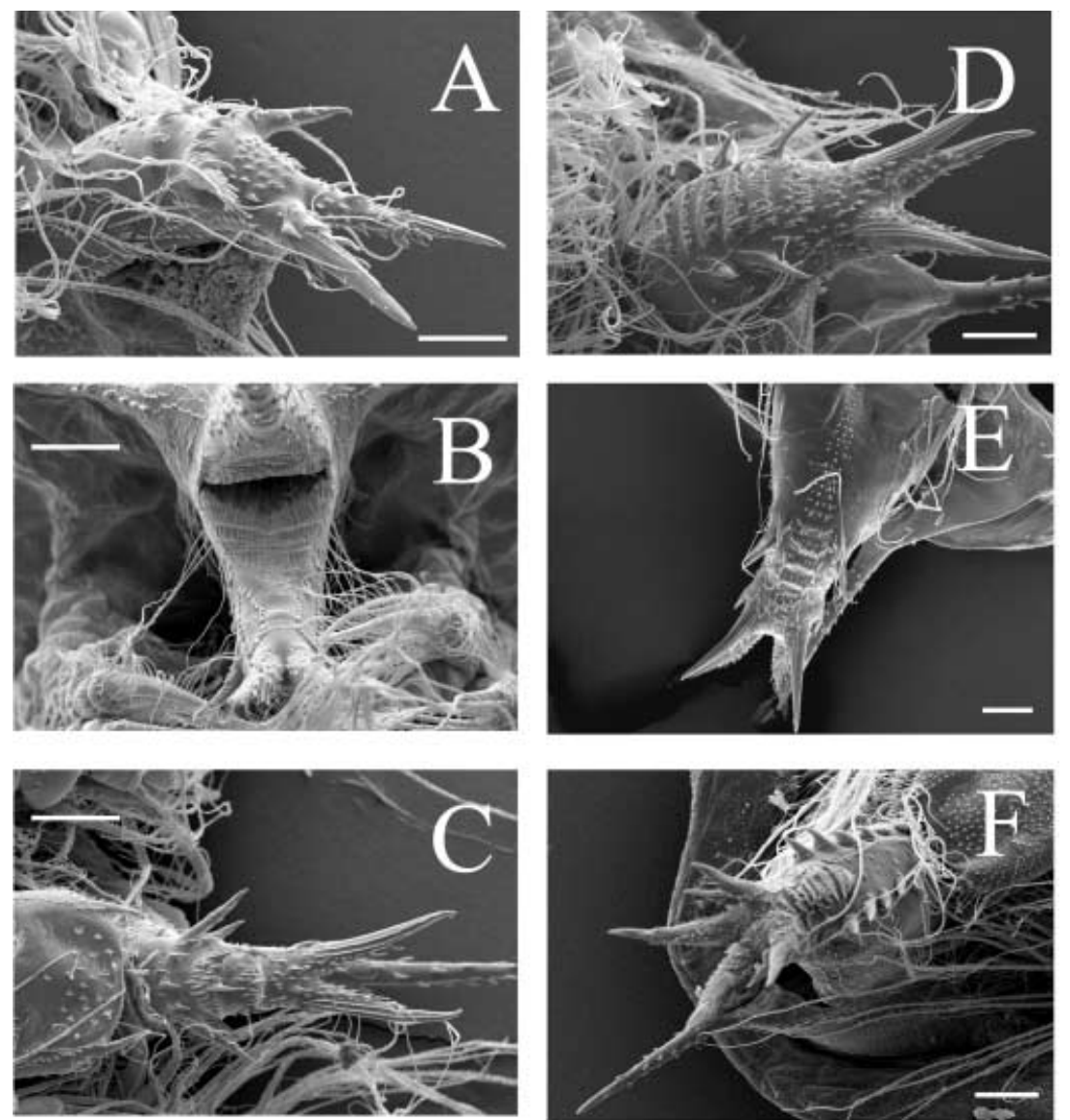

Figure 5. Thoraco-abdominal process of naupliar stages II to VI of Chthamalus malayensis: (A, G-F) ventral views; (B) dorsal view, at stage II. Scale bar: $20 \mu \mathrm{m}$.
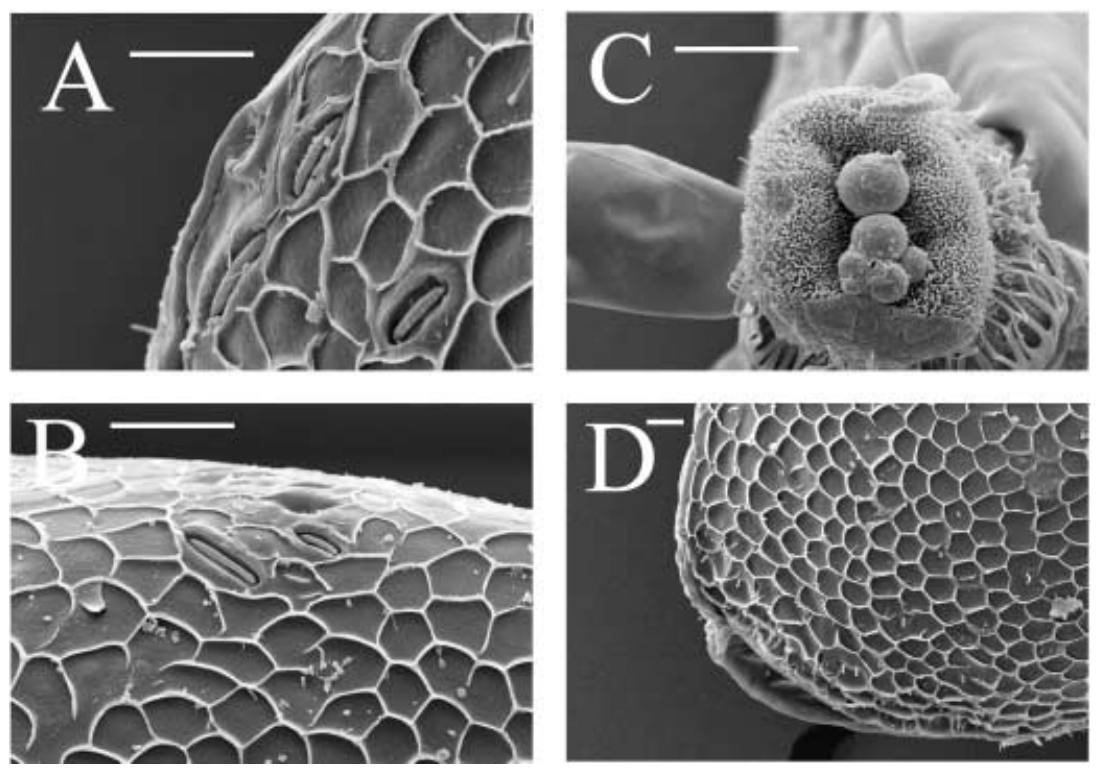

Figure 6. Surface structures of a cyprid of Chthamalus malayensis: (A) three posterior lattice organs; (B) two anterior lattice organs; $(\mathrm{C})$ shape of third segment; and (D) setae. Scale bar: $10 \mu \mathrm{m}$.

part of the shield (Figure 2). The frontolateral horns are bent slightly in an anterior direction when compared to stage I and have $16-18$ pores (Figure $3 \mathrm{~A}$ ); a short dorsal stylet is present which is not fused with the rim of the open distal end of the horn. The labrum bears 5-9 spines plus slender setae (Figure 4A,B). A pair of frontal filaments was observed on the anterior side which continue to be present in all the subsequent stages. The dorsal thoracic spine has small teeth and is longer than the abdominal process, which has a pair of large serrated spines (series 1) and a bifurcated ramus (Figure 5A,B). 


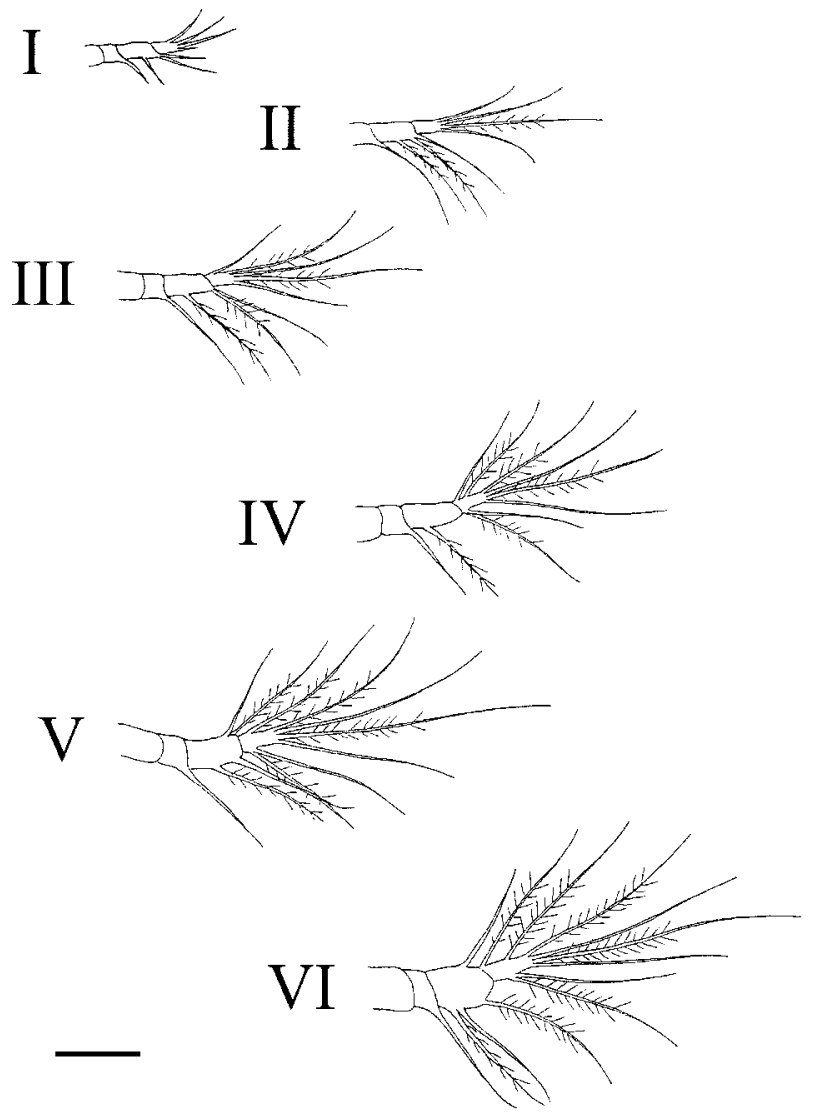

Figure 7. Antennules of naupliar stages I-VI of Chthamalus malayensis. Scale bar: $100 \mu \mathrm{m}$.

\section{Nauplius III}

The larva (Figure 1B) has increased in total length $(379 \mu \mathrm{m})$ and width $(267 \mu \mathrm{m})$ when compared to stage II. Similar to stage II, one pair of lateral spines and eight pairs of pores appear on the dorsal cephalic shield surface: two pairs of pores on the anterior, three anterior lateral, three posterior lateral, and a further two pairs of pores on the central area of the dorsal surface: one anterior and another posterior (a total 22 pores, Figure 2). The frontolateral horns have become thickened and shorter in length (Figure 3B). The ventral perforations have been lost and the structural arrangement at the distal end is altered. Two teeth on each posteriolateral margin of the labrum (Figure 4G) and a preaxial seta present on the antennules are diagnostic features of stage III nauplii. The dorsal thoracic spine is now barbed and consistently longer than the abdominal process. A row of four spines with spinules appears behind the series 1 spine (Figure 5C).

\section{Nauplius IV}

This stage (Figures 1C) has the caudal spine separated from the cephalic shield. In addition to the 22 pores arranged on the dorsal cephalic shield (see in stage III), another three pairs of pores on the central area of the dorsal surface are present, giving a total of 28 pores (Figure 2). The frontolateral horns of this stage are different from those of stage III (Figure 3G), but remain morphologically similar in subsequent stages
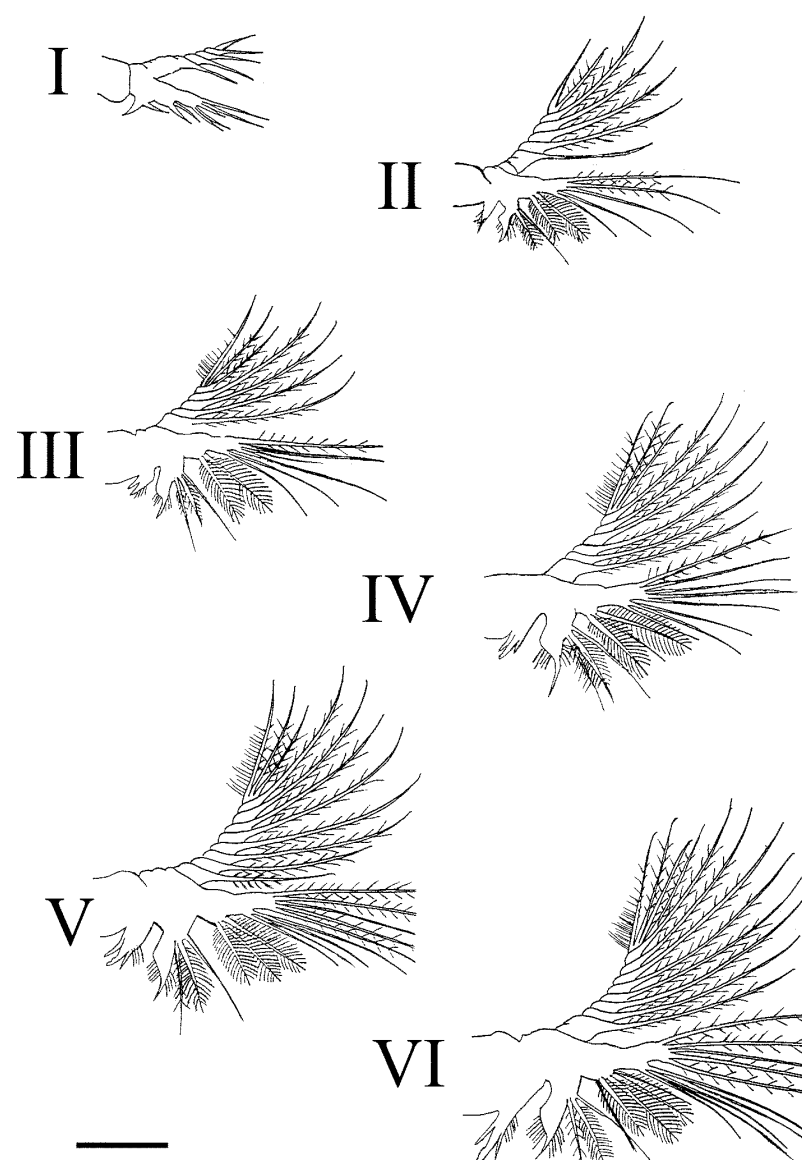

Figure 8. Antennae of naupliar stages I-VI of Chthamalus malayensis. Scale bar: $100 \mu \mathrm{m}$.

(Figure 3D,E). There is a fine dorsal spine, a ventral spine and a row of tapering filaments surrounding the distal end of the horns. An additional pair of lateral teeth occur on the labrum (Figure 4D) which together with the presence of two pre-axial setae on the antennules are diagnostic features of this nauplius stage. The second pair of large spines (series 2) has emerged close to the base of the furca and the dorsal thoracic spine is still longer than the abdominal spine (Figure 5D).

\section{Nauplius $V$}

The cephalic shield has increased in size (Table 3), but the general shape remains similar through to nauplii VI (Figure 1D). The position and number of pores on the dorsal surface of the cephalic shield remain the same. The number of teeth on the labrum of this stage (Figure 4E) is the same as for stage IV, and subsequently stage VI (Figure $4 \mathrm{~F}$ ), except that the number of spines on the surface of the labrum varies. The dorsal thoracic spine remains barbed, but is now shorter than the abdominal process where a third pair of spines (series 3) has appeared (Figure 5E). The presence of three pre-axial and five postaxial setae on the antennules is a diagnostic feature of this nauplius stage.

\section{Nauplius VI}

The body shape of this stage (Figure 1E) is similar to stage $\mathrm{V}$ except in size. In the latter development of this stage, a pair of compound eyes becomes clearly visible on 


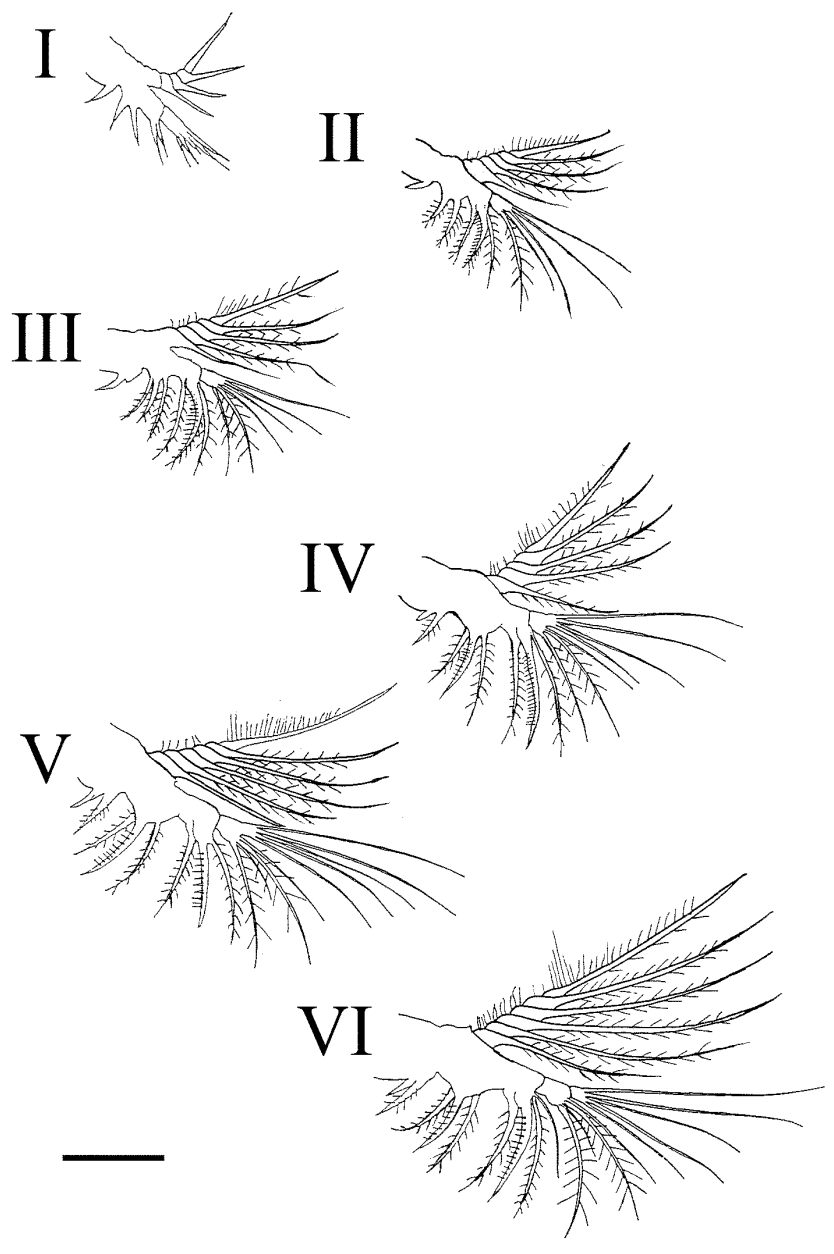

Figure 9. Mandibles of naupliar stages I-VI of Chthamalus malayensis. Scale bar: $100 \mu \mathrm{m}$.

either side of the median nauplius eye. The nauplius VI stage is easily distinguished from other stages by the six pairs of thoracic spines occurring on the abdominal process and the primordia of the cypris thoracic appendages beneath the exoskeleton of the thoracic spines (Figure 5F). Three distal teeth are present on the inner prong of the antennal gnathobase of the third group of endopodites of this stage, similar to those of stages III $-\mathrm{V}$.

\section{Cyprid}

The bivalve carapace of the cyprid (Figure $1 \mathrm{~F}$ ) is $425 \mu \mathrm{m}$ in mean total length and $221 \mu \mathrm{m}$ in mean height (Table 3). The anterior region of the body contains numerous oil droplets. There are six pairs of thoracic limbs and a posterior caudal furca. Median and compound eyes are present in the anterior region of this larva. Under the SEM, the carapace surface has a honeycombed pattern with a large number of small projecting setae, which are uniformly distributed over the entire carapace (Figure 6D). Five pairs, two anterior (Figure 6B) and three posterior (Figure 6A), of lattice organs ( $\mathrm{LO})$ are also obvious. The antennule ends in a cup-shaped third segment consisting of an almost circular attachment disc, a raised rim (velum or skirt) and sense organs (Figure 6C).

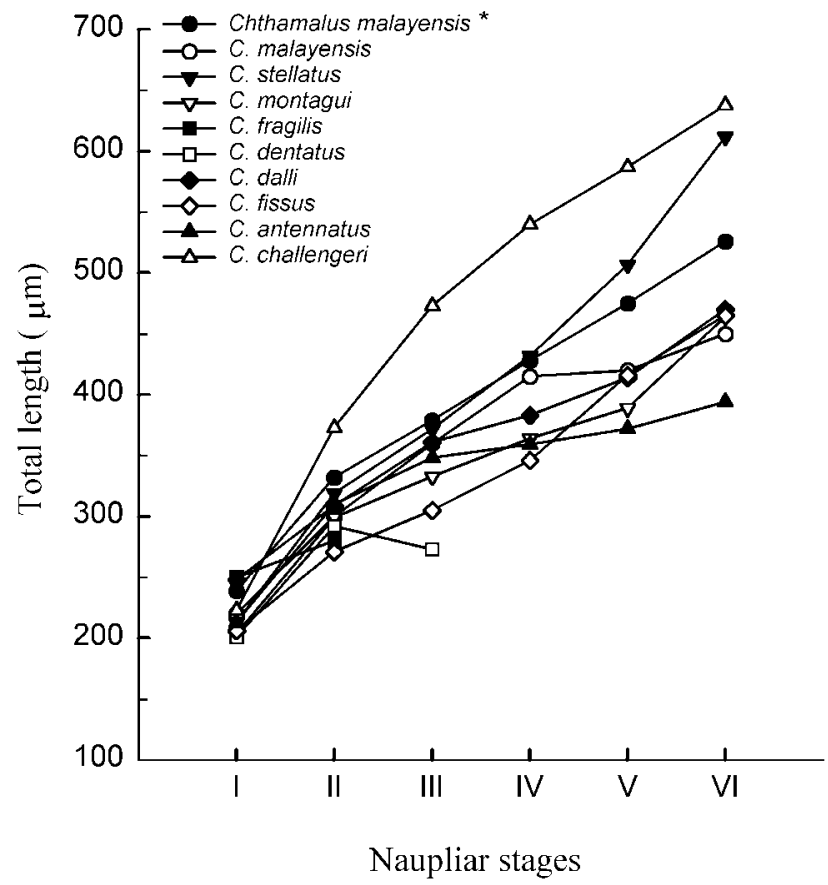

Figure 10. Total length $(\mu \mathrm{m})$ of naupliar stages of Chthamalus malayensis* (present study), C. malayensis (Karande \& Thomas, 1976), C. stellatus and C. montagui (Burrows et al., 1999), C. fragilis (Lang, 1979), C. dentatus (Achituv, 1986), C. dalli and C. fissus (Miller et al., 1989), C. antennatus (Egan \& Anderson, 1989) and C.challengeri (Lee, 1999).

\section{DISCUSSION}

Comparison of the larval description of Chthamalus malayensis in the present study with that of Karande $\mathbb{}$ Thomas (1976)

\section{Larval development}

Observations showed that Chthamalus malayensis requires at least 20 days to reach the cypris stage under laboratory culture at $21^{\circ} \mathrm{C}$. This period was longer than for the same species from Mumbei, India, which only required 7-12 days (Karande \& Thomas 1976). The difference may be due to the culture temperatures employed. Although Karande \& Thomas (1976) did not give their culturing temperature, when other batches of larvae in the present study were cultured at $28^{\circ} \mathrm{C}$, cyprids appeared within 14 days.

\section{Larval morphology}

The present larval observations of C. malayensis differ from those of Karande \& Thomas (1976) with regard to larval size and morphology, such as spines along the posterior lateral margin of the cephalic shield at stages II and III, thoraco-abdominal process at stage II and stage IV, teeth of the labrum and setation of the antennae (Table 4), possibly reflecting ecological and biogeographical variation.

\section{Comparison with other Chthamalus species}

\section{Larval size and shape}

Comparison of size ranges among Chthamalus species show that the nauplii of $C$. malayensis occur in the middle of the range (Figure 10). The nauplii of 
C. challengeri are the largest at every larval stage and the larvae of $C$. fragilis and $C$. antennatus are smallest. In some cases, the size of larvae at each stage is probably the simplest distinguishing character i.e. between C. stellatus and C. montagui (Burrows et al., 1999), and also separates C. fragilis and C. dalli at the same stages (Miller \& Blower, 1989). The size of larvae reared in the laboratory, however, is often of little value in the identification of species, as variation in culture conditions such as temperature (Miller \& Blower, 1989; Burrows et al., 1999), larval density (Lewis, 1975) and food types (Stone, 1988) can affect larval size.

Shield length was approximately equal to shield width (ratio=1.01-1.03) in C. malayensis, which is similar to other Chthamalus species (ratio of length to width=1.0-1.15; Lang, 1979; Achituv, 1986; Miller et al., 1989; Egan \& Anderson, 1989; Burrows et al., 1999; Lee, 1999). Shield shape, therefore, is not a diagnostic character to separate species in the genus Chthamalus.

\section{Sculpturing of the cephalic shield}

There is no recorded information about the dorsal surface sculpturing of the cephalic shield in Chthamalus nauplius larvae and very little for the Cirripedia in general. Scanning electron microscopy images of Semibalanus balanoides nauplii showed 32 dorsal pores and two pairs of minute, mid-dorsal setae on the cephalic shield surface in the sixth nauplius stage (Walker \& Lee, 1976). In the present study, the nauplii of C. malayensis have 22 dorsal pores at stage III and 28 at stage IV and also one pair of frontal setae from stages II-VI. These observations might provide useful for future comparative studies of the sculpturing of the cephalic shield of cirripede nauplii. It is likely that the dorsal ornamentation of the cephalic shield and the number and positions of the pores and setae may vary from species to species.

\section{Labrum}

The teeth of the labrum in Chthamalus species are a diagnostic character in the separation of the larval stages of a given species and also the larvae of different species. In $C$. malayensis, the teeth of the labrum are very useful in distinguishing stages II, III and IV larvae. The unilobed labrum has 5-9 teeth at stage II, one pair of teeth at the corners of the free distal end at stage III, and two pairs of teeth from stages IV-VI. A similar pattern has also been observed in C. stellatus, C. montagui, C. fissus and C. dalli. The teeth of the labrum of some $C$. malayensis stages, however, are different from those of $C$. antennatus, C.dentatus, $C$. fragilis and $C$. challengeri. The setose labrum in stages IV, V and VI of $C$. antennatus have two lateral teeth on the distal margin (Egan \& Anderson, 1989), whereas in C. dentatus, the labrum at stage IV has a pair of lateral teeth (Achituv, 1986). The labrum in C. fragilis has small denticles at stage II and two pairs of lateral teeth separated by numerous small denticles, which are lost at stage VI, and a median protuberance that becomes increasingly larger in later stages (Lang, 1979). The labrum has slender setae with sparse teeth from stage II to stage VI in C. challengeri (Lee, 1999).

\section{Abdominal processes}

At all six stages, the pattern and emergence of spines on the abdominal process observed in $C$. malayensis was the same as that in C. montagui, C. stellatus, C. dalli and C.fissus, $C$. antennatus and C. fragilis, except for stage III. There are no differences in the abdominal process between larvae in stages II and III for some Chthamalus species, such as C. montagui, C. stellatus, C.dalli, C. fissus, C. antennatus, C. fragilis, C. challengeri and C. dentatus (Lang, 1979; Achituv, 1986; Egan \& Anderson, 1989; Miller et al., 1989; Burrows et al., 1999; Lee 1999), although differences are present in Chthamalus malyensis between nauplius II and III. In nauplius II of $C$. malayensis, only a group of fine spinules on the posterior trunk were observed, but in nauplius III, two rows of fine spinules with some bigger spinules (3-4) were present.

\section{Setation of appendages}

Little attention has been paid to the morphological variability of the antennal coxal gnathobase in nauplii of Chthamalus species. The gnathobases of two Chthamaloid species (Octomeris sulcata and $C$. challengeri) and one Lepadomorph (Capitulum mitella) barnacle were reported to be very similar to each other with two distal teeth on the inner prong of the antennal gnathobase (Kado \& Hirano, 1994). Scanning electron microscopy images of the antennal gnathobases of Chthamalus malayensis revealed three teeth on the inner prong of the antennal gnathobase, which indicates there are differences between C. malayensis and C. challengeri, suggesting the antennal gnathobase may be a useful feature to separate Chthamalus species.

The review of larval morphology in the nine Chthamalus species from a wide geographic range suggests that the differences in size of larvae, the shape and teeth of the labrum, the number and position of abdominal process spines and setation of appendages are important features to separate the nauplii of Chthamalus species.

This study was supported by a University of Hong Kong (HKU) research studentship to Y.Y. We are grateful to Dr Gray A. Williams for critical review of the manuscript. The authors would also like to thank Dr A.A. Karande from the Naval Materials Research Laboratory, India and Dr C. Lee from the Aquaculture Division, East Sea Regional Fisheries Research Institute, National Fisheries Research \& Development Institute, Korea for providing references. We are also in debt to Dr G. Walker from School of Ocean Sciences, University of Wales, Bangor, for giving information on larval SEM investigations and $\mathrm{Mr}$ Lee from the SEM Unit of HKU for providing assistance in SEM sample preparation.

\section{REFERENCES}

Achituv, Y., 1986. The larval development of Chthamalus dentatus Krauss (Cirripedia) from South Africa. Crustaceana, 51, 259-269.

Bassindale, R., 1936. The developmental stages of three English barnacles, Balanus balanoides (Linn.), Chthamalus stellatus (Poli), and Verruca stroemia (O.F. Müller). Proceedings of the Zoological Society of London, 106, 57-74.

Branscomb, E.S. \& Vedder, K., 1982. A description of the naupliar stages of the barnacles Balanus glandula Darwin, Balanus cariosus Pallas, and Balanus crenatus Bruguière (Cirripedia, Thoracica). Crustaceana, 42, 83-95. 
Burrows, M.T., Hawkins, S.J. \& Southward, A.J., 1999. Larval development of the intertidal barnacles Chthamalus stellatus and Chthamalus montagui. Fournal of the Marine Biological Association of the United Kingdom, 79, 93-101.

Clare, A.S. \& Nott, J.A., 1994. Scanning electron microscopy of the fourth antennular segment of Balanus amphitrite amphitrite. Fournal of the Marine Biological Association of the United Kingdom, 74, 967-970.

Daniel, A., 1958. The development and metamorphosis of three species of sessile barnacles. Fournal of the Madras University, B, 28, 23-47.

Egan, E.A. \& Anderson, D.T., 1989. Larval development of the chthamaloid barnacles Catomerus polymerus Darwin, Chamaesipho tasmanica Foster and Anderson, and Chthamalus antennatus Darwin (Crustacea: Cirripedia). Zoological Journal of the Linnean Society, 95, 1-28.

Elfimov, A.S., 1995. Comparative morphology of the thoracican cyprid larvae: studies of the carapace. In New frontiers in barnacle evolution (ed. F.R. Schram and J.T. Høeg), pp. 137-152. Rotterdam: A.A. Balkema. [Crustacean Issues, no. 10.]

Glenner, H. \& Høeg, J.T., 1995. Scanning electron microscopy of cyprid larvae in Balanus amphitrite amphitrite (Crustacea: Cirripedia: Thoracica: Balanomorpha). Fournal of Crustacean Biology, 15, 523-536.

Kado, R. \& Hirano, R., 1994. Larval development of two Japanese megabalanine barnacles, Megabalanus volcano (Pilsbry) and Megabalanus rosa (Pilsbry) (Cirripedia, Balanidae), reared in the laboratory. Fournal of Experimental Marine Biology and Ecology, 175, 17-41.

Karande, A.A., 1999. Notes on SEM study of cirriped Chthamalus challengeri larvae. Indian fournal of Marine Sciences, 28, 81-82.

Karande, A.A. \& Thomas, M.K., 1976. The larvae of the intertidal barnacle Chthamalus malayensis Pilsbry. Proceedings of Indian Academy of Sciences, 83B, 210-219.

Korn, O.M., 1995. Naupliar evidence for cirripede taxonomy and phylogeny. In New frontiers in barnacle evolution (ed. F.R. Schram and J.T. Høeg), pp. 87-122. Rotterdam: A.A. Balkema. [Crustacean Issues, no. 10.]

Korn, O.M. \& Ovsyannikova, I.I., 1979. Larval development of the barnacle Chthamalus dalli. Biologiya Morya, 5, 60-69.

Landau, M. \& d'Agostino, A., 1977. Enhancement of laboratory cultures of barnacle Balanus eburneus Gould using antibiotics. Crustaceana, 33, 223-225.

Lang, W.H., 1979. Larval development of shallow water barnacles of the Carolinas (Cirripedia: Thoracica) with keys to naupliar stages. National Oceanic and Atmospheric Administration Technical Report, NMFS, no. 421, 1-39.
Lee, C., 1999. Larval development of Chthamalus challengeri Hoek (Cirripedia: Thoracica: Chthamalidae) with keys to barnacle larvae of Korean coastal waters. Korean Fournal of Biological Sciences, 3, 59-68.

Lewis, C.A., 1975. Development of the gooseneck barnacle Pollicipes polymerus (Cirripedia: Lapadomorpha): fertilization through settlement. Marine Biology, 32, 141-153.

Miller, K.M., 1994. Descriptions of the larvae of Tetraclita rubescens and Megabalanus californicus with a comparison of the common barnacle larvae of the central California coast. Fournal of Crustacean Biology, 14, 579-600.

Miller, K.M. \& Blower, S.M., 1989. Comparison of larval and adult stages of Chthamalus dalli and Chthamalus fissus (Cirripedia: Thoracica). Journal of Crustacean Biology, 9, $242-256$.

Morton, B. \& Morton, E., 1983. The seashore ecology of Hong Kong. Hong Kong: Hong Kong University Press.

Moyse, J., Høeg, J.T., Jensen, P.G. \& Al-Yahya, H., 1995. Attachment organs in cypris larvae: using scanning electron microscopy. In New frontiers in barnacle evolution (ed. F.R. Schram and J.T. Høeg), pp. 153-178. Rotterdam: A.A. Balkema. [Crustacean Issues, no. 10.]

Newman, W.A., 1965. Prospectus on larval cirriped setation formulae. Crustaceana, 9, 51-56.

Pope, E.C., 1965. A review of Australian and some Indomalayan Chthamalidae (Crustacea, Cirripedia). Proceedings of the Linnean Society of New South Wales, 90, 10-77.

Rainbow, R.S. \& Walker, G., 1976. The feeding apparatus of the barnacle nauplius larva: a scanning electron microscope study. Fournal of the Marine Biological Association of the United Kingdom, 56, 321-326.

Stone, C.J., 1988. Test of sequential feeding regimes for larvae of Elminius modestus Darwin (Cirripedia: Balanomorpha). Fournal of Experimental Marine Biology and Ecology, 115, 41-51.

Walossek, D., Høeg, J.T. \& Shirley, T.C., 1996. Larval development of the rhizocephalan cirripede Briarosaccus tenellus (Maxillopoda: Thecostraca) reared in the laboratory: a scanning electron microscopy study. Hydrobiologia, 328, 9-47.

Walker, G. \& Lee, V.E., 1976. Surface structures and sense organs of the cypris larva of Balanus balanoides as seen by scanning and transmission electron microscopy. Fournal of Zoology, 178, 161-172.

Submitted 3 April 2001. Accepted 25 June 2001. 